\title{
Analisis Kualitas Pelayanan Menggunakan Metode Service Quality dan Diagram Kano untuk Meningkatkan Kepuasan Nasabah di Bank Jabar Banten Syariah Cabang Bandung
}

\author{
Alvin Cakra Pratista* \\ Prodi Manajemen, Fakultas Ekonomi dan Bisnis, Universitas Islam Bandung, \\ Indonesia. \\ *alvinpratista069@gmail.com
}

\begin{abstract}
The purpose of this study was to determine the customer service banking services at the Bank Jabar Banten Syariah in Bandung and measure the services at the Bank Jabar Banten Syariah in Bandung using the service quality analysis method and canoe diagrams. This type of research used in this research is descriptive quantitative and for the method of research using descriptive case studies that focus intensively on one particular object, by studying case studies. The population in this study is a customer of Bank Jabar Banten Syariah as consumers of Bank Jabar Banten Syariah banking services and has a sample of 114 people. Data collection techniques used in this study were interviews with back office staff employees and auditors, surveys and observations. The results of this study revealed that the services provided by the Bank Jabar Banten Syariah in Bandung included in the category quite well, but in research using service quality analysis of services provided by the Bank Jabar Banten Syariah in Bandung branch have shortcomings in terms of open customer service in exchanging ideas, customer service is able understand the needs, customer service conveys information, customer service master the field of work, customer service provides patient service, technology and customer service equipment. While the CS-Coefficient calculation results showed the highest better value of 1.02 in the 23rd service attributes, 13, 23 and 25, namely customer service hospitality, accuracy of customer service in service, customer service providing convenient service, and worse value equal to -1.49 in the 15 th service attribute, namely the ability to communicate customer service.
\end{abstract}

Keywords: Service quality, Service quality method, canoe model.

\begin{abstract}
Abstrak. Tujuan penelitian ini adalah untuk mengetahui layanan customer service perbankan pada jasa Bank Jabar Banten Syariah cabang Bandung serta mengukur pelayanan jasa di Bank Jabar Banten Syariah cabang Bandung dengan menggunakan metode service quality analysis dan kano diagram. Jenis penelitian yang digunakan pada penelitian ini adalah deskriptif kuantitatif dan untuk metode penelitian menggunakan deskriptif studi kasus yaitu memusatkan diri secara intensive terhadap satu objek tertentu, dengan cara mempelajari studi kasus. Populasi pada penelitian ini merupakan nasabah Bank Jabar Banten Syariah selaku konsumen dari jasa perbankan Bank Jabar Banten Syariah dan memiliki sampel sebanyak 114 orang. Teknik pengumpulan data yang digunakan pada penelitian ini adalah wawancara dengan karyawan staff back office dan auditor, survey dan observasi. Hasil penelitian ini mengungkapkan bahwa pelayanan yang diberikan Bank Jabar Banten Syariah cabang Bandung termasuk kedalam kategori cukup baik, namun pada penelitian menggunakan service quality analysis pelayanan yang diberikan Bank Jabar Banten Syariah cabang Bandung memiliki kekurangan dalam hal customer service terbuka dalam bertukar pikiran, customer service mampu memahami kebutuhan, customer service menyampaikan informasi, customer service menguasai bidang pekerjaannya, customer service memberikan pelayanan dengan sabar, tekhnologi dan peralatan customer service. Sementara hasil perhitungan CS-Coefficient menunjukan nilai better yang paling tinggi sebesar 1,02 pada atribut layanan ke-23 yaitu 13, 23 dan 25, yaitu keramahtamahan customer service, keakuratan customer service dalam melayani, customer service memberikan layanan yang nyaman, dan nilai worse sebesar -1,49 pada atribut layanan ke-15, yaitu kemampuan berkomunikasi customer service.
\end{abstract}

Kata Kunci: kualitas pelayanan, metode Service quality, model Kano. 


\section{A. Pendahuluan}

Perbankan merupakan lembaga keuangan yang bertugas menghimpun dan menyalurkan dana di masyarakat untuk meningkatkan taraf hidup di masyarakat. Bank Syariah merupakan bank yang kegiatannya mengacu pada hukum Islam, dan dalam kegiatannya pun tidak membebankan pada bunga kepada nasabah. Bank Jabar Banten Syariah merupakan suatu lembaga keuangan yang memiliki tujuan untuk dapat membantu para nasabahnya dalam mengelola finansial mereka.

Bank Jabar Banten Syariah berhasil meraih penghargaan Infobank Banking Service Excellence Award 2016 dengan predikat "Pertama". Namun itu tidak menjadikan Bank Bjb Syariah menjadi pilihan nomor 1 para nasabah. Hal ini dikarenakan nasabah mengeluhkan kurangnya variasi produk dan layanan yang ditawarkan di Bank Jabar Banten Syariah, serta buruknya fasilitas yang terdapat di Bank Jabar Banten Syariah.

Berdasarkan latar belakang yang telah diuraikan, maka perumusan masalah dalam penelitian ini sebagai berikut:

1. Untuk mengetahui kualitas pelayanan yang di lakukan di Bank Jabar Banten Syariah.

2. Untuk mengetahui kualitas pelayanan dengan menggunakan metode Service Quality dan Diagram Kano untuk meningkatkan kepuasan nasabah di Bank Bjb Syariah.

\section{B. Landasan Teori}

Secara umum Manajemen Operasi merupakan bidang manajemen yang bersangkutan dengan merancang dan mengendalikan proses produksi. Manajemen ini juga bisa dimanfaatkan untuk mendesain ulang operasi bisnis dalam produksi barang atau jasa. Manajemen operasi adalah area bisnis yang berfokus pada proses produksi, serta memastikan pemeliharaan dan perkembangan berlangsung secara efektif dan efesien.

Pengendalian kualitas merupakan upaya untuk melaksanakan fungsi manajemen dalam kegiatan operasi. Fungsi tersebut yaitu pengendalian, manajemen operasi memfokuskan pengendalian terhadap kualitas dari barang dan jasa yang akan dihasilkannya.

Kualitas layanan adalah penilaian nasabah perihal seberapa baik pelayanan tersebut dalam memenuhi harapan nasabah. Kualitas pelayanan berkaitan dengan konsep persepsi dan ekspektasi.

Model Kano dikembangkan oleh Noriaki Kano (Kano dalam Toni Wijaya, 2011:258). Model kano adalah model yang bertujuan untuk mengkategorikan atribut-atribut dari produk maupun jasa berdasarkan seberapa baik produk tersebut mampu memuaskan kebutuhan pelanggan. Atribut-atribut layanan dapat dibedakan menjadi beberapa kategori, yaitu must be, one-dimensional, attractive, indiferrent, questionable, reversal.

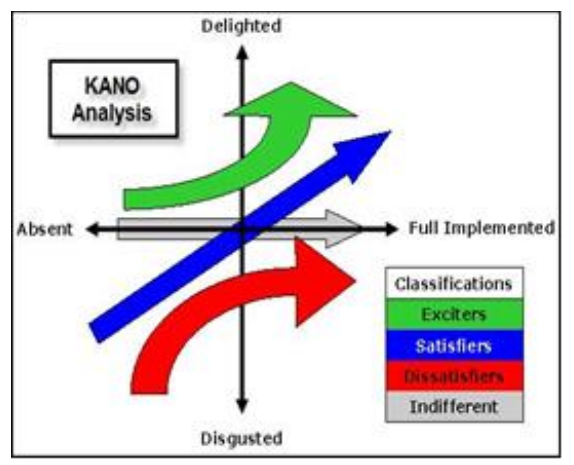

Gambar 1. Diagram Kano Analisis

\section{Hasil Penelitian dan Pembahasan}

Data Deskriptif Demografi Respornden 
Responden berjenis kelamin perempuan memiliki angka yang lebih tinggi dengan jumlah 68 responden atau 59,65\% dan jumlah responden laki-laki yaitu 48 atau 40,35\%. Selanjutnya data deskriptif kedua yaitu sampel setiap kantor Bank Jabar Banten Syariah di Bandung adalah dari Kantor Pusat Braga Bank Jabar Banten syariah adalah 24 responden atau 21,05\%, Kantor Cabang Pembantu Sukajadi Bank Jabar Banten syariah adalah 76 atau 66,67\%, Kantor Cabang Pelajar Pejuang 14 atau $12,28 \%$

\section{Hasil Perhitungan Service Quality}

Tabel 1. Hasil Perhitungan Gap score

\begin{tabular}{|c|c|c|c|c|c|c|c|}
\hline & $\begin{array}{c}\text { Mean } \\
\text { Persepsi }\end{array}$ & $\begin{array}{c}\text { Mean } \\
\text { Ekspektasi }\end{array}$ & $\begin{array}{c}\text { Gap } \\
\text { Score }\end{array}$ & & $\begin{array}{c}\text { Mean } \\
\text { Persepsi }\end{array}$ & $\begin{array}{c}\text { Mean } \\
\text { Ekspektasi }\end{array}$ & $\begin{array}{c}\text { Gap } \\
\text { Score }\end{array}$ \\
\hline P1 & 4,15 & 4,12 & 0,03 & P16 & 3,6 & 3,89 & $-0,29$ \\
\hline P2 & 3,71 & 3,7 & 0,01 & P17 & 3,74 & 3,73 & 0,01 \\
\hline P3 & 3,78 & 3,77 & 0,01 & P18 & 3,6 & 3,91 & $-0,31$ \\
\hline P4 & 3,64 & 3,63 & 0,01 & P19 & 4,1 & 4,02 & 0,08 \\
\hline P5 & 3,68 & 3,65 & 0,03 & P20 & 3,61 & 3,98 & $-0,37$ \\
\hline P6 & 3,74 & 3,71 & 0,03 & P21 & 3,75 & 3,74 & 0,01 \\
\hline P7 & 3,69 & 3,68 & 0,01 & P22 & 3,67 & 3,66 & 0,01 \\
\hline P8 & 3,76 & 3,74 & 0,02 & P23 & 3,96 & 3,91 & 0,05 \\
\hline P9 & 3,69 & 3,68 & 0,01 & P24 & 3,75 & 3,73 & 0,02 \\
\hline P10 & 3,69 & 3,67 & 0,02 & P25 & 3,76 & 3,7 & 0,06 \\
\hline P11 & 3,62 & 3,61 & 0,01 & P26 & 3,62 & 3,92 & $-0,30$ \\
\hline P12 & 3,74 & 3,72 & 0,02 & P27 & 4,08 & 3,92 & 0,16 \\
\hline P13 & 4,04 & 4,02 & 0,02 & P28 & 3,75 & 3,8 & $-0,05$ \\
\hline P14 & 3,44 & 3,89 & $-0,45$ & P29 & 3,44 & 3,93 & $-0,49$ \\
\hline P15 & 3,96 & 3,89 & 0,07 & P30 & 3,64 & 3,62 & 0,02 \\
\hline
\end{tabular}

Dengan demikian atribut layanan yang perlu diperbaiki oleh pihak Bank Jabar Banten Syariah adalah atribut layanan yang memiliki kategori yang lemah hasil tersebut didapatkan berdasarkan perhitungan dari service quality analysis. Berdasarkan data yang sudah ada, maka didapatkan sebanyak 6 atribut layanan yang lemah dan perlu diperbaiki dan diperhatikan oleh pihak Bank Jabar Banten Syariah. Atribut-atribut layanan tersebut adalah: customer service terbuka dalam bertukar pikiran yang memiliki nilai gap sebesar $-0,45$, customer service mampu memahami kebutuhan memiliki nilai sebesar $-0,29$, customer service menyampaikan informasi dengan jelas memiliki nilai sebesar $-0,31$, customer service menguasai bidang pekerjaannya memiliki nilai sebesar-0,37, customer service memberikan pelayanan dengan sabar memiliki nilai sebesar-0,30, tekhnologi dan peralatan customer service memiliki nilai sebesar $-0,49$.

\section{Hasil Perhitungan Diagram Kano}

\section{Better}

\section{Better (kepuasan)}

$$
\frac{A+O}{A+O+M+I}
$$


Gambar 2. Rumus Better

Tabel 2. Hasil Perhitungan Better

\begin{tabular}{|c|c|c|c|c|c|}
\hline & $\begin{array}{c}\text { Kategori } \\
\text { Kano }\end{array}$ & Better & & $\begin{array}{c}\text { Kategori } \\
\text { Kano }\end{array}$ & Better \\
\hline P1 & M & 1,01 & P16 & M & 1,01 \\
\hline P2 & M & 1,01 & P17 & M & 1,01 \\
\hline P3 & M & 1,01 & P18 & M & 1,01 \\
\hline P4 & M & 1,01 & P19 & M & 0,96 \\
\hline P5 & M & 1,01 & P20 & M & 0,96 \\
\hline P6 & M & 1,01 & P21 & O & 0,97 \\
\hline P7 & M & 1,01 & P22 & M & 0,96 \\
\hline P8 & M & 1,01 & P23 & O & 1,02 \\
\hline P9 & O & 0,99 & P24 & M & 1,01 \\
\hline P10 & O & 0,99 & P25 & O & 1,02 \\
\hline P11 & O & 0,98 & P26 & M & 0,83 \\
\hline P12 & M & 0,95 & P27 & M & 0,84 \\
\hline P13 & O & 1,02 & P28 & A & 0,94 \\
\hline P14 & M & 1 & P29 & A & 0,96 \\
\hline P15 & M & 1,01 & P30 & M & 0,94 \\
\hline
\end{tabular}

Hasil perhitungan dari atribut layanan menggunakan metode diagram kano untuk mengetahui nilai better atau nilai kepuasan konsumen akan meningkat dengan adanya keberadaan atribut tersebut. Dimana nilai better paling tinggi menunjukan pada atribut layanan ke-13, ke-23 dan ke-25, yaitu keramahtamahan customer service dalam melayani, keakuratan customer service dalam melayani dan customer service memberikan layanan yang nyaman dengan nilai better sebesar 1,02 hal tersebut menunjukan pelanggan atau nasabah akan meningkat kepuasan terhadap layanan tersebut karena pada layanan tersebut menunjukan nilai better yang tinggi dibandingkan dengan atribut layanan yang lainnya.

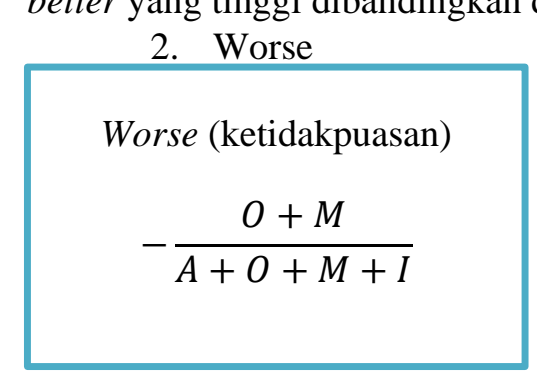

Gambar 3. Rumus Worse

Tabel 3. Hasil Perhitungann Worse

\begin{tabular}{|c|c|c|c|c|c|}
\hline & $\begin{array}{c}\text { Kategori } \\
\text { Kano }\end{array}$ & Worse & & $\begin{array}{c}\text { Kategori } \\
\text { Kano }\end{array}$ & Worse \\
\hline P1 & M & $-1,42$ & P16 & M & $-1,27$ \\
\hline P2 & M & $-1,42$ & P17 & M & $-1,49$ \\
\hline
\end{tabular}




\begin{tabular}{|c|c|c|c|c|c|} 
P3 & $\mathrm{M}$ & $-1,42$ & $\mathrm{P} 18$ & $\mathrm{M}$ & $-1,29$ \\
\hline P4 & $\mathrm{M}$ & $-1,3$ & $\mathrm{P} 19$ & $\mathrm{M}$ & $-1,48$ \\
\hline P5 & $\mathrm{M}$ & $-1,28$ & $\mathrm{P} 20$ & $\mathrm{M}$ & $-1,36$ \\
\hline P6 & $\mathrm{M}$ & $-1,28$ & $\mathrm{P} 21$ & $\mathrm{O}$ & $-1,13$ \\
\hline P7 & $\mathrm{M}$ & $-1,27$ & $\mathrm{P} 22$ & $\mathrm{M}$ & $-1,48$ \\
\hline P8 & $\mathrm{M}$ & $-1,27$ & $\mathrm{P} 23$ & $\mathrm{O}$ & $-1,19$ \\
\hline P9 & $\mathrm{O}$ & $-1,1$ & $\mathrm{P} 24$ & $\mathrm{M}$ & $-1,02$ \\
\hline P10 & $\mathrm{O}$ & $-1,1$ & $\mathrm{P} 25$ & $\mathrm{O}$ & $-1,19$ \\
\hline P11 & $\mathrm{O}$ & $-1,09$ & $\mathrm{P} 26$ & $\mathrm{M}$ & $-1,18$ \\
\hline P12 & $\mathrm{M}$ & $-0,95$ & $\mathrm{P} 27$ & $\mathrm{M}$ & $-1,31$ \\
\hline P13 & $\mathrm{O}$ & $-1,17$ & $\mathrm{P} 28$ & $\mathrm{~A}$ & $-0,75$ \\
\hline P14 & $\mathrm{M}$ & $-1,02$ & $\mathrm{P} 29$ & $\mathrm{~A}$ & $-0,73$ \\
\hline P15 & $\mathrm{M}$ & $-1,49$ & $\mathrm{P} 30$ & $\mathrm{M}$ & $-1,08$ \\
\hline
\end{tabular}

Hasil perhitungan dari atribut layanan menggunakan metode diagram kano untuk mengetahui nilai worse atau nilai kepuasan konsumen akan menurun jika tidak adanya keberadaan atribut tersebut. Dimana nilai worse paling tinggi menunjukan pada ke-17, yaitu meyakinkan nasabah dalam menggunakan produk, dengan nilai worse sebesar 0,84 . Hal tersebut menunjukan pelanggan atau nasabah akan menurun kepuasannya terhadap layanan kemampuan berkomunikasi customer service dan customer service dapat meyakinkan nasabah dalam menggunakan produk, karena pada layanan tersebut menunjukan nilai worse yang tinggi dibandingkan dengan atribut layanan yang lainnya.

\section{Kesimpulan}

Berdasarkan pembahasan dalam penelitian ini, peneliti menyimpulkan beberapa hasil penelitian sebagai berikut:

1. Kualitas layanan jasa perbankan yang dilakukan Bank Jabar Banten Syariah dengan menggunakan metode Service Quality Analysis berada pada kontinum cukup baik. Dengan menggunakan metode service quality analysis bahwa terdapat 24 atribut layanan akademik yang kuat atau memiliki hasil nilai gap score yang positif dan terdapat 6 atribut layanan yang lemah atau memiliki hasil nilai gap score yang negatif yang perlu diperbaiki dan diperhatikan oleh pihak Bank Jabar Syariah.

2. Dengan menggunakan metode diagram kano masing-masing dari kategori memiliki nilai better dan nilai worse yang berbeda-beda pada setiap atribut layanan. Atribut yang memiliki pengaruh tertinggi terhadap kepuasan dan ketidakpuasan pada masing-masing kategori dapat dilihat dari nilai better dan nilai worse yang tertnggi. Hasil perhitungan koefisien kepuasan konsumen atau CS-Coefficient menunjukan bahwa nilai better paling tinggi pada kategori Kategori $\mathrm{M}$ (must be) adalah atribut customer service terbuka dalam bertukar pikiran dan memberikan perhatian pada nasabah. Kategori $\mathrm{O}$ (one-dimensional) adalah atribut keramahtamahan customer service. Kategori A (Attractive) adalah teknologi dan peralatan customer service. Nilai worse paling tinggi pada kategori M (must be) adalah kemampuan berkomunikasi customer service dan kemampuan meyakinkan nasabah dalam menggunakan produk. Kategori O (onedimensional) keramahtamahan customer sevice dan keakuratan customer service dalam melayani. Pada kategori A (Attractive) adalah kondisi perlengkapan meja kerja customer service, teknologi dan peralatan customer service

\section{E. Saran}


1. Sebaiknya Customer service terbuka dalam bertukar pikiran, mampu memahami kebutuhan, menyampaikan informasi dengan jelas, menguasai bidang pekerjaannya, memberikan pelayanan dengan sabar, diberikan tekhnologi dan peralatan yang memadai.Hendaknya penelitian selanjutnya dapat melanjutkan penelitian ini dengan membahas mengenai keputusan pembelian produk dari konsep perilaku konsumen, agar dapat diketahui sejauhmana terpaan iklan dapat mempengaruhi perilaku konsumen untuk membeli produk berdasarkan iklan yang disaksikannya.

2. Sebaiknya layanan yang perlu di tingkatan untuk kategori $\mathbf{M}$ (must be), customer service menguasai produk, kesiapan dalam melayani nasabah, kehandalan layanan, ketepatan waktu yang disediakan, memberikan kesalahan minimum, kecepatan dalam melayani, kesediaan dalam melayani nasabah, tanggap dalam melayani nasabah, kemampuan berkomunikasi, mampu memahami kebutuhan, dapat meyakinkan nasabah dalam menggunakan produk, menyampaikan informasi dengan jelas, memberikan perhatian pada nasabah. Untuk kategori A (Attractive), teknologi dan peralatan customer service. Untuk kategori O (One-dimensional), customer service ramah dalam melayani, keakuratan dalam melayani, memberikan layanan yang nyaman

\section{Daftar Pustaka}

[1] Bakhtiar, A, Aries, S., dan Fildariani, M. 2010. Analisis Kualitas Pelayanan Yang Berpengaruh Terhadap Kepuasan Pelanggan Menggunakan Metode

[2] Daft, Richard L. (2012) Manajemen. Edisi 1, Alih Bahasa Oleh Edward Tanujaya Dan Shirly Tiolina. Salemba Empat, Jakarta.

[3] Febriyanti, T. S. (2014). Pengaruh Product Quality, Service quality, Brand Image, Dan Customer Satisfaction Terhadap Custumer Loyalty Pada Pembelian Lipstik Revlon Di Aci Kosmetik Balikpapan (Doctoral Dissertation, Universitas Pelita Harapan SurabayaDepartment Of Business Scholl-Faculty Of Management).

[4] Herjanto, E. 2007. Manajemen operasi edisi 3. Grasindo

[5] Pawitra, Teresia, Rosita Mitha, Eka Irawati.2007. Pengukuran tingkat kepuasan pelanggan dengan memperhatikan aspek Kano Model. Proceeding seminar

[6] Nasional, Vol 2. Hal 291-298.

[7] Mustaniroh S, Lestari E, dan Sari E. 2010. Penilaian Kepuasan Konsumen Terhadap kualitas Pelayanan Menggunakan Metode Servqual (Service Quality) (Studi Kasus Pada "WAROENG X" Cab. Soekarno Hatta-Malang). Jurnal Teknologi Pertanian 11(6):152161.

[8] Slack, N., Chambers, S. \& Johnston, R., 2010. Operations Management, 6th

[9] Satria Utama. 2017. Laporan Akhir Survei Customer Study Bank BJB Syariah. RAD Research

[10] Widjoyo, I. O., Rumambi, L. J., dan Kunto, Y. S., 2013. Analisa Pengaruh Kualitas layanan terhadap Kepuasan Konsumen pada Layanan Drive Thru McDonald's Basuki Rahmat di Surabaya. Jurnal Manajemen Pemasaran, Vol. 1(1): 1-12

[11] Prof. Dr. Muhardi (2011). Manajemen Operasi 